Parental choice of childcare in England: choosing in phases and the split market

Huan Chen, Northeast Normal University, Institute of Education Alice Bradbury, University College London, Institute of Education

Correspondence details:

Huan Chen

Northeast Normal University, Institute of Education

130024, 5268 Renmin Road

Changchun, China

huan.chen.17@alumni.ucl.ac.uk 


\title{
Parental choice of childcare in England: choosing in phases and the
}

\author{
split market
}

\begin{abstract}
This article explores how parents choose childcare settings for their preschool children within a context of complex policy on eligibility for free provision and a developing market. Using data from interviews with 17 mainly middle-class parents in England, we explore in detail how parents go about choosing a childcare setting and the different phases of this process. This adds further nuance to the existing literature on choosing practices and the dysfunction and inequalities of neoliberal childcare market, and also updates the discussion to include recent policy developments such as the provision of ' 30 hours free childcare' for three and four-year-olds. We conclude that parental choosing involves a series of decisions in two or three phases, which start from practical considerations, followed by quality comparison and then back to practical constraints if decision has not been made. The options open to parents are split between not only those able to accommodate shorter 'free' provision and those that require longer periods of childcare to work, but also between those with children under three and above. Contrary to previous findings in this area, this split may work to disadvantage some middle-class families whose children attend lower quality settings as a result. (197 words)
\end{abstract}

Key Words: parental choice, childcare market, early education and care, middle class

\section{Introduction}

This article explores the childcare choosing practices of parents in England. The childcare market in England is diverse, made up of both state and private providers offering a range of different forms of childcare and education, and policy intervention in the form of free provision further complicated this complex picture. While previous research has been carried on the factors or constraints involved in parental choosing, it is still not clear when parents consider these factors during the decision-making process, and how these chains of decisions operate. This study attempted to understand how different factors influence parents' decisions during the complex choosing process under the English childcare policy and market context, and to what extent they fall into the existing conceptual framework. The research data suggest a complex model of parental childcare choosing with a series of decisions coming along in a process of two or three phases, which adds to the existing models of parental childcare choosing, and 
offers important insights into the dysfunction and inequalities of neoliberalism childcare market within the current policy context.

The paper is divided into three parts. The first part considers past and current literature and policy trends in this area, as well as introducing the research methods utilized in this study. The second part presents the identified three phases of parental choosing, through which parents mapped and located the provider they were going to use. The following part discusses in depth the theory and policy implications of the three phases and their interactions. The parental experiences presented here provide unusual examples of how middle-class parents can feel they are in a disadvantaged position with very limited choices, and how market choosing reproduces inequalities within the middle class in a complex way.

\section{Background}

\subsection{Literature Review}

Evidence suggests that childcare choice plays a vital role in maternal labour force participation (Boll and Lagemann, 2019) and there is a strong link between child care and child outcome (Grogan, 2012; Azpitarte, 2016). Therefore, investigating parental childcare choosing has been a continuing concern of academics, especially in Anglophone countries where a marketized approach is applied, notably the UK, the US, New Zealand, Canada and Australia.

The economic model of childcare consumption is based on assumptions about individuals being rational decision makers, and thus this model expects parents to maximize their satisfaction by considering the trade-offs between waged work versus childcare prices and/or quality (Blau et al., 2002; De Macro, 2006). Extensive research has demonstrated that higher price or lower perceived quality has negative impact on the use of non-parental childcare, especially centre-based care (Powell, 2002; Gameren, 2013). This basic model has been extended to focused on parents' choices among various type of childcare, for example, centre-based formal childcare versus informal childcare. Findings suggest that childcare arrangement is a constrained optimization problem, where families' decisions are subject to constraints, for instance, the age of children (Huston, Chang \& Gennetian, 2002), family structure such as the number of children and co-residence of adults (Johansen et al., 1996; Anderson et al., 2005) and family budget (Capizzano \& Adams, 2004).

In two reviews in 2006 and 2010, another two frameworks were highlighted and a new framework was proposed. (Meyers \& Jordan, 2006; Chaudry et al., 2010) A heuristics and biases framework suggested that human decisions are more biased than rational, given the fact that the calculus of trade-offs will be influenced by psychological factors such as education and cultural background (Radey \& Brewster, 2007), or mothers' attitude towards childcare and employed mothers (Gameren, 2013). A social network framework views parental childcare choosing as a product of social interaction. It specially emphasises the importance of social networks, which 
not only provide information and support but also shape reputations and pressure. Based on the contributions and limitations of the previous framework, an integrated 'accommodation model' was suggested to argue that childcare choice is complex, fluid and has multiple determinants, and that families "accommodate" to opportunities and constraints determined by a wide range of factors, among which family needs, family resources, cultural norms and preferences, as well as contextual opportunities and constraints were in the centre. (Meyers \& Jordan, 2006; Chaudry et al., 2010) Coley et al (2014) developed Meyers and Jordan's (2006) theory by linking the factors with children period of development.

Although this body of international work is considerable, thus far, however, few authors have been able to draw on in-depth qualitative research into when and how various factors influence parents' decision-making processes specifically. Moreover, as Chaudry, Henly and Meyers (2010) suggest, the applicability of each research is limited by the contextual policy and nature of the market. For example, the analysis of Raikes et al. (2012) reported "whether the provider was licensed or accredited" as one of the key criteria used by American parents, while this may not apply to countries where there is a compulsory registration and inspection system, as in the UK. Surprisingly, although it is now well established from a variety of research that a complex and unequal pattern of childcare use amongst English parents exists (Vincent et al., 2001, 2004, 2006, 2010; Gambaro, Stewart \& Waldfogel, 2015; Speight et al., 2015; Huskinson et al. 2016), there has been little detailed investigation of current parental childcare choosing process given the unique English childcare market features. For example, the extent to which parents consult Ofsted reports has remained unclear. Drawing upon the existing research, this study attempts to conduct an exploration into parents' childcare choosing process and investigate how this English experience contributes to the international discourse.

\subsection{Policy context}

Driven by the increasing demand of non-parental childcare (OECD, 2004), and an internationally growing intention to invest in the first years of children's lives in order to combat child poverty (Penn, 2005) and reduce expenditure at later stages (Dahlberg et al, 2013), childcare for preschoolers has become a key political concern in many Western welfare states. In England, the sector has seen profound change not only in unprecedented state intervention, but also an ongoing movement towards a neoliberal market approach (Gallagher, 2018; Mahon, 2010). The expansion of public sector is restricted by the law (Childcare Act 2006), making state provision the 'last resort' (Stewart \& Gambaro, 2014). Instead, the market is purported to be the most efficient way of meeting childcare demands (OECD, 2004). Parents are imagined as rational consumers in the marketplace seeking out the service that best meets their needs, whilst the state supports parental purchase by decreasing childcare expenses (in the forms of tax and welfare programmes, as well as free hours). In order to guarantee the childcare quality provided by various providers, the UK government has constructed an exceptionally tight regulatory framework including the EYFS statutory framework 
as well as compulsory Ofsted registration and inspection. Authors have questioned the managerialism, performativity (Hunkin, 2016, 2018a, 2018b) and compatibility (Adamson \& Brennan, 2014) of this policy landscape, especially how Ofsted accreditation relies on the assumption that quality is objective, universal and can be specifically measured (Dahlberg et al, 2013).

Under this discourse of the neoliberal market, childcare services in England are underpinned by a mixed economy composed of diverse providers: private nurseries (catering for a range of age ranges), school-based nursery classes (for age 3-4 and occasionally age 2-4), nursery schools (age 3-4 and occasionally age 2-4), childminders (who look after children in their home), and nannies (who work in the child's home). Recently, a number of key changes have affected the operation of the market, especially the eligibility of free hours at registered settings for three and fouryear-olds as well as 'disadvantaged' two-year-olds ${ }^{1}$. At the time this research was conducted, families with two working parents were able to access 30 hours of free childcare for children over the age of three, at least in theory (DfE, 2018). In practice, however, partly due to the low levels of government funding for these 'free' hours (BBC News, 2018), childcare costs in England are noted to be higher than many other countries (Harding \& Cottrell, 2018). Also, there are concerns that the lower quality requirements for PVI sector goes against the genuine policy idea of 'level playing field' (West \& Noden, 2018), and that the take-up rates of free hours are lower in areas with higher child poverty rates (Campbell, Gambaro \& Stewart, 2018).

\section{The research study}

The research was conducted in 2017/2018 academic year as part of a wider project exploring the childcare market in England. A research method of semi-structured qualitative interviews was utilised in order to gain insights into participants' personal decision-making process. The sample $(n=17)$ was consisted of parents who had selected a childcare provider at some point over the last ten years, though most had done this more recently. Parents were recruited through a variety of channels, including through contacts, through nurseries involved in the wider project, and in response to a call for participants circulated through the researchers' university-based networks. The respondents were variously from what Savage et al. (2013) called 'Traditional working class'( $n=2)$, 'New affluent workers'( $n=1)$, 'Technical'/ 'Established' middleclass $(n=11)$ and 'Elite' $(n=3)$ based on occupation, ownership of property and household income. Table 1 presents information about how the participants were recruited, participants' background and the free hours they used. Here 'top up' indicates that they also paid for additional hours. Note that some parents did not have children eligible for free hours. While the project aimed to consider all parents, in line with similar studies, all the participants who agreed to take part were women.

\section{[Table 1 here]}

The research was conducted within the ethical guidelines provided by the British 
Education Research Association and the UCL Institute of Education. The interviews either took place in a separate room in the nursery, in the participant's home, or by skype. The average length of the interview was 30 minutes. Interview questions focused on the process of choosing childcare and parents' reasoning. All the interviews were transcribed, resulting in over 50400 words of transcription. During the data analysis process, an open coding approach was applied, which then lead into axial coding and selective coding. (Charmaz, 2006) First, codes were given to the factors that emerged from parents' explanation. Then the transcription was printed out and cut into pieces of various length based on the issues they were addressing. Transcription of similar codes were assorted together to go into the third step of conceptualizing the commonalities, which resulted in seven factors of decision making. Subsequently, all the factors were reviewed to analysis how and when do they affect parents' decision. Although the analysis process was grounded on the original data, the previous research gave many insights to the first phase of choosing identified in this research, which is mapping available choices by given constraints.

\section{Findings}

Overall the findings suggest that there are three phases to choosing childcare, with different concerns during each phase. Our findings confirm those from previous research which suggest 'parental decisions around childcare are a complex mixture of practical and moral concerns, and social relations are at least as important as economic relations (Vincent et al. 2010; p284). However, we find that this mixture varies at each phase of the choosing process, beginning with the practical considerations.

\subsection{Phase one of parental choice: dealing with practical constraints}

\section{Age range and opening hours: "It's just realistically it's the only way that my life would work."}

The first consideration was the age range and opening hours of different providers. When full-time working parents (usually middle class or more affluent) first come to the situation of choosing a childcare service, not all the provision types are open to them. The fact that state early years provision mainly contributes to services for 3- to 4- year old children means that parents of younger children have to choose between employing a nanny, paying a childminder and or enrolling their child at a day nursery. Even for children over three, parents who work a full day still cannot send their children to school nurseries or nursery schools because the short length of sessions offered (usually only three hours in the mornings or afternoons) means they are unable to work a full day. In other words, the market of ECEC is split not only between 0-3 and 3-5 years old, but also between parents who work full-days and those who do not, which leads to the fact that parents choose from different positions within the market structure.

Most people got their children in day nurseries because they are working. Because nurseries that are attached to school, whether private or state run, tend to finish at 12. So if you are working, it's impossible. (Wendy) 
It can be clearly seen from Table 2 that private day nurseries are the option that most participants considered or used. For the nine parents who enrolled their children in a day nursery, except Fiona who also employed a nanny, it is the only option that suited their family and life arrangements when their children are under 2 or 3 years old (Chole, Wendy, Eva and Holly) or for the whole below 5 childcare phase (Isla, Becky, Daisy and Phoebe). All are middle-class or elite parents.

\section{[Table 2 here]}

The pattern reveals the fact that social and economic background can shape the spectrum of choice that parents have, echoing the findings of a consumer choice framework (Blau, 2001; Blau et al., 2002). As they discuss, parents with a salary higher than the price of childcare are more likely to pay for childcare to maximize their financial benefits. However, our research also shows that regardless their willingness to pay, many busy working middle-class parents are tightly constrained to day nurseries and childminders because of the extended service age and opening hours that are provided. Although Vincent et al (2010) suggested that middle-class parents are more skilled, more informed and more careful in their decision-making process, the simple practical consideration of being able to work and travel to work meant that for many of our respondents, their choice was limited by practicality, however skilled or informed they were about their options.

\section{Other practical constraints and considerations: "I was a terrible mum, I chose by convenience."}

In the previous section, we discussed the first practical reason of parent choice, which is the age range and opening hours of different providers. The next element of practical parental choosing is to further cut down the available choices based on information about available providers, geographic location, finance and availability of the places.

\section{Information about available providers}

Our investigation showed that parents may not logically map all the available choices based on sound information. Becky reported that she made an 'emergency' decision on her way to work when she 'drove past' a nursery. Another five parents based their choices on fragmentary information from previous personal experiences or significant others. Lily sent her daughter into the same school that all her family attended; Ruby chose a childminder who she knew previously; Holly chose the provider suggested by neighbour just after her daughter was born while Fiona chose the one affiliated to her synagogue. Only Carol compared nurseries suggested by her friends before making any decision. Four of these (with the exception of Lily and Carol) were middle-class parents.

A total of 12 parents actively conducted a general search on Google $(n=3)$, Facebook $(n=2)$ and local council websites/information sheets $(n=7)$, although six of them 
combined a general search with asking for recommendation from friends or other parents (Isla, Jessica, Georgia, Joan, Chole, Holly). It is interesting to note that Holly actively engaged in a searching process to find an under two-years-old place for her daughter, which suggests that parents' utilization of information is dynamic rather than having any pre-decided pattern. All the six parents who had a combined source of information put more emphasis on 'word of mouth', and some complained that the local council website which they used was 'not very detailed' (Isla) and 'could definitely do better' by adding 'what parents like about it'(Maya).

Even a school or nursery is open with you, it doesn't necessarily mean you'll get the full picture. So I think it's quite important to grab a talk with the parents before. (Chole)

The findings above suggest that social networks possibly play a more important role than some research has expected, where Vincent et al. (2010) found middle-class parents actively engage in a choice-seeking process. Although Holly recalled how she make sure she 'knows all the options' while Jessica said she only looked at three nurseries 'even though there were seven or eight on the list', this study adds more complexity to the pattern. In addition, while previous research has established the imperfect features of parents' utilization of information in the childcare market, there are various explanation available. The Consumer Choice Framework suggested parents heavily rely on social contacts because the available information was incomplete itself, while the Heuristics and Biased Framework explained as individuals were more likely to be influenced by information that can be mentally accessed easily. (Chaudry, Henly \& Meyers, 2010). Given the fact that the English childcare market is supported by local council information services and Ofsted quality reports, which are supposed to have a key role in reducing information asymmetry, this research supports the Heuristics and Biases Framework to a larger extent.

\section{Location}

Geographic location was the most frequently mentioned issue $(n=12)$. Among the other five parents, four of them were either not working (Grace), only worked part-time (Maya, Carol), or had a flexible working schedule (Eva). Noticeably, there were two variables observed about this factor. Firstly, mothers tend to put more emphasis on location when it came to their first time of choosing. Secondly, the factor tends to have more significant impact due to the lack of information and/or the similarity of available choices, while the significance degraded as parents get more experienced in choosing childcare.

When we first moved to this area, she went to a different nursery. There was one around the corner and one near the station. And she went to the one by the station. I chose that ... I was a terrible mum. I chose it for convenience 'cause it was right around the station. (Wendy) 
This finding strongly echoes the Accommodation Model which suggested that although parents always seek to satisfy preferences, the preferences themselves are dynamic and context-dependent, and may vary according to past experience and changed family or workplace situations (Chaudry, Henly \& Meyers, 2010).

\section{Cost}

It is notable that affordability does not seem to be a significant factor influencing parents' decisions. Among the 17 respondents, only Grace initiatively stated that price influenced her decision. By responding to a researcher-initiated question, only two parents (Becky and Georgia) suggested they considered or being influenced by the factor of price. This is perhaps because most of our respondents are middle-class or elite parents and are financially able to pay for childcare, while those less affluent parents were only using free hours in public provision (Lily, Carol and Jessica). In spite of that, there were some comments about the high cost, especially towards the option of hiring a nanny:

So it was about $£ 35,000$ a year in the year that I had nannies. It is very expensive. (Fiona)

It's expensive, very expensive. After paying for the house, it's the most expensive thing every month. So a huge amount of money, particularly in London. It's like paying for private school, or probably more expensive. Because there's no school holiday and you pay for every single day. (Isla)

However, parents also showed positive attitude towards paying the fees, reporting that they are 'totally supportive'(Chole) and 'chose to spend' (Wendy) that amount of money. Again, this phenomenon falls into the Consumer Choice Framework (Blau, 2001; Blau et al., 2002) because parents sacrifice some of their financial benefits in exchange of satisfying their quality preference, which results in an overall satisfaction.

\section{Availability and time pressure}

Respondents reported that the overall available places might be sufficient for the area but there may not be available places at the particular time when they need it. Thus, availability could induce panic and force parents choose the 'secure' option:

So at the time we were looking, we contacted a few childminders and we would have to go through a long waiting list. And that just did not seem... it seems too much risk to take 'cause I have to go back to work at a particular time. (Daisy)

Here we see the affective dimension of childcare choice, where fear and risk are factors interfere in the decision-making process. This is particularly acute if there are time pressures on parents to choose: 
I drove passed it on my way to work. And I saw their own advertising, signs and so on. So we stopped on my way home and said could I make an appointment to talk to someone... It was an emergency kind of option. I have to say I did not look at other nurseries. (Becky)

These findings reflect those work of Mittelstaedt, Duke and Mittelstaedt (2009) as well as Huff \& Cotte (2013), who found that time pressure brings negative emotions to childcare choice process. Although the Accommodation Model (Chaudry, Henly, \& Meyers, 2010) is a more advanced framework drawing from previous literature, it fails to recognize that factors like time pressure will 'interfere' the process of decision making which is already a product of contextual constrains and social norms. The function of time pressure or time associated availability is different from other factors as it 'interferes' with the decision-making process as a 'outside' factor rather than going consciously/un-consciously into parents' minds and functioning inter-dependently with other factors.

A total of 13 parents (with the exception of Lily, Ruby, Becky, Fiona and Holly) went through the first phase and continued into the second phase of quality comparison. Note that Holly adopted different choosing strategies for under two-years-old and older.

\subsection{Phase two of parental choice: quality comparison}

After selecting several settings based on practical considerations, the next concern of the 13 parents who had not already made a choice was quality. In order to get a precise picture of parents' quality consideration in this phase, this study used the established quality assessment tool ECERS-R to map the quality aspects that parents mentioned. As can be seen from Table 3, except for the subscale of 'Language and Reading', all the other quality subscales were covered by parents, though much more emphasis was put into General Supervision of Children $(n=17)$ in the subscale of Interaction. However, among the 43 quality items of ECERS-R, 14 of them weren't mention by parents, whilst 4 Non-ECERS-R factors were introduced by parents, respectively Building $(n=2)$, Ratio/Group Size $(n=6)$, Children's Emotional Well-being $(n=13)$ and Staff Structure $(n=5)$.

[Table 3 here]

\section{Parents' quality judgement: 'Get a feeling for what you like.'}

Interestingly, parents frequently used the affective term 'feel' when talking about quality. For instance, 'so I had a good feeling which I had for example for this place' (Grace), 'Just a general feel of the place' (Wendy), 'I would say go to a few of them, get a feeling for what you like' (Holly). Jessica reported that it is easy to 'get a feel of the place', 'as soon as you go into the nursery'. However, Phoebe and Joan suggested its vague nature:

I don't think there was anything wrong with it (a nursery). I just didn't like it. 
I guess the only analysis I can say is that sometimes you met people and you just don't click with them. You just don't get along with them. There's nothing wrong with that person. I guess, you know, you just don't really sort of get along with them. I guess the same thing. It's very emotional, sort of emotional feeling. (Phoebe)

I do think instinct is very important, I really do. You know you meet someone, you know if you are happy if they can take care of your child. (Joan)

This can shed lights on why all the participants agreed it is important for the general supervision of children to form a friendly, welcoming, attentive and nurturing atmosphere, and $76 \%$ of the participants suggested they observed children's emotional well-being to see if they were happy and confident. Parents tend to judge childcare quality in a holistic and subjective way, relying on their 'feel' and 'instinct', which just match with the features of the two factors. Thus, it is justified to announce that parents' judgement of childcare quality is more holistic, emotional and subjective than rational.

\section{Ofsted ratings and reports: "It's a starting point."}

Except for Lily and Wendy who clearly stated that Ofsted did not affect their childcare decision, all the other parents stated Ofsted ratings and/or reports were a factor that they took into consideration. For instance, Georgia suggested that 'as a parent you have no idea', 'you need something to look at, to give you some kind of information'. Maya and Eva emphasized how Ofsted inspection gave them 'confidence' about the nursery, especially in terms of safety issues. Apparently, a good or outstanding Ofsted label played a key role to motivate them to consider their chosen nursery as an option in the first place. This observation may support the hypothesis that the system of Ofsted can tackle information asymmetry and equip parents to make more informed decision, which in turn decrease the danger of 'adverse selection' where parents choose low quality providers due to lack of information (Mocan, 2007).

However, 12 out of the 15 parents seem to be influenced to a lesser extent, as they felt that the information coming from Ofsted is 'just a starting point' (Holly), or there to 'cloud your judgement' (Carol). Concerns were expressed about some of the drawbacks of Ofsted system, for example, the cycle of inspection being too long to offer a full picture of the quality (Phoebe), the focus of inspection is 'much more on the preschool level' (Daisy), as well as providers might get outstanding report out of 'pleasing' the inspector (Isla) and vice versa (Joan). A common view amongst interviewees were that Ofsted report was a 'dry document' (Chole) because it does not reflect children's 'whole day experience' (Daisy). As Holly said, the choice of childcare is a 'personal preference', which involves knowing the place and meeting the staff:

The more I learn about it, the more I realize it's actually personal preference. And when you meet the people and meet the staff and how you feel they'll treat your children. And how they do treat other children and their ethos. That's 
the most important thing. So I think it's quite dangerous that people would just look at the Ofsted report because you are not seeing the full picture. (Holly)

But I think you have to go and SEE the nursery. I don't think you can really just go on the inspection report. You need to see where your child is going to be every day and what the people are like there. (Isla)

Interestingly enough, the reason for the two mothers not to check public inspection results is somewhat similar, with Lily reporting she 'knew people from old time' and it was 'definitely a place' she 'feel comfortable with', whilst Wendy said 'you can't know what the life is' from a document. In addition, eight participants indicate that they would not pursue an 'outstanding' rating as long as they felt a provider 'would work' for their children (Isla, Chole, Carol, Maya, Holly, Daisy, Phoebe and Joan). These findings echo the previous observation of how parents' judgement of quality might differ from a professional and regulatory perspective by being holistic and emotional (Katz, 1993).

\section{Staff and qualifications: 'It's all about people'}

Although the importance of staff qualifications on childcare and education quality is evidenced (Nutbrown, 2012; Mathers et al., 2011), it was not a significant factor for parental childcare choice. Only two parents clearly stated that they considered the benefits of having qualified teachers during their choosing process (Becky, Joan), while others ( $\mathrm{n}=12)$ were comfortable with the 'minimum qualification requirement' (Holly), and more concerned about the 'personality' and 'attitude' (Joan) of staff as well as their interaction with children:

It's less about qualifications. Ultimately, I felt I wanted people who ... the most important thing in the end was people who care for my children, would look after them, and a lot of that is into a personal basis as oppose to having information. (Daisy)

Again, we see here how emotive the issue of childcare choice is, particularly for parents of younger children, who prioritized their children being 'cared for' over qualifications. The lack of concern over qualifications means there is little incentive for private nurseries to recruit more highly trained (and more expensive) staff due to market competition.

\section{Quality expectations in a split market: "That's what you are looking for for a day nursery."}

Finally in this phase, we note that there was clear evidence of different expectations of quality in different sections of the market. Although it has been over 10 years since EYFS was first introduced to provide integrated early childhood education and care, inconsistency can still be witnessed from a parental perspective. The seven respondents who compared day nurseries with other provision types all chose other options (Lily, Grace, Carol, Jessica, Maya, Georgia, and Joan). Those who used nursery schools or 
nursery classes in schools reported that their experience of the quality differed.

It's more about your child will be fed and clean and safe. That's what you are looking for for a day nursery. (Fiona)

Any learning they get is more coincidental rather than the purpose of it. I think... when you get into this nursery school, you would see that their plans and their schedules and their objectives... At the childcare setting you will see on the wall that what are the menus for the week, that kind of thing. (Fiona)

One of the underlying logics of the early years market is that parental choice would lead to competition between providers and thus encourage them to attract customers by improving service quality and flexibility. However, although nursery schools hire a large proportion of qualified teachers and provide the highest quality of early education in England (Gambaro et al, 2015; Melhuish \& Gardiner, 2017), they do not necessarily 'compete' with other providers like day nurseries and childminders in terms of the different service they are providing (particularly shorter hours). As a result, they do not act as a market incentive to motivate quality improvement generally.

\subsection{Phase three of parental choosing: return to practical consideration}

A total of 11 parents chose their childcare option by the end of the second phase of quality comparison. For two parents (Wendy and Phoebe) who found the quality of nurseries had a high level of similarity, however, there was a final stage of further practical consideration.

The one I chose, I think for... for that sort of age group it tends to be very similar to the day nursery, I don't think there's much difference between the two of them, and between nurseries generally I've looked at. And I chose one that was convenient for me to go to work. (Wendy)

We put our son's name down on the waiting list for both of them. And then one of them have place came first, so we took it. I'm sure it would probably be same as nice things if we go to the other one. (Phoebe)

In conclusion, there are mainly two phases to childcare choosing, which involve practical constraints and quality evaluation respectively, although some parents may go back to practical considerations if they have not made their decision after the second phase - here relating to location and availability. The figure below represents these different phases, and how they follow each other and also overlap.

[Figure 1 here]

\section{Discussion}

This study aimed to understand the processes involved in parents' formal childcare 
choices in English policy context, with a focus on how different factors influence parents' decisions. The findings reported here suggest that parental choices are made over a series of decisions in a process of two or three phases. The first phase of choosing involves practical constrains and considerations, including the provided age range and opening hours, information about available providers, location, cost, availability and time pressure. If there are still various options after ruling out some settings based on practical issues, then parents will go into the second phase of evaluating service quality. Generally, in this phase parents relied on a holistic, emotional and subjective 'feeling' of the place, which specially emphasis the general supervision of children to form a friendly, welcoming, attentive and nurturing atmosphere, as well as children being happy and confident. Parents might return to practical considerations after phase two, particularly about availability and location if they find the available choices were similar in quality. The three phases presented here add further nuance to accounts of how parents choose childcare in a marketplace and emphasizing again the importance of emotion and affect in these decisions.

The findings contribute to the existing parental childcare choosing conceptual frameworks in various ways. First, the Consumer Choice Model and Accommodation Model suggest childcare arrangements as a subject to constrains (Blau et al., 2002; Meyers \& Jordan, 2006; Chaudry, Henly, \& Meyers, 2010; Liu, 2015), while this study brings clearance by explaining 'structural' constrains of the market in the English case. As discussed, the English childcare market is split not only between full-time working parents and their peers in part-time work or at home, but also between those providing for children under three years old and those for three to five years old. With different family needs, particularly maternal employment and family income, parents have chosen different childcare providers (Liu, 2015), which implies that various social class functions in a different position of the market. Although middle-class or more affluent parents have a range of resources available to them in terms of finances and decisionmaking skills (Vincent et al., 2010), they might not have the privilege of flexibility which Emlen (2010) has highlighted as the key for 'childcare puzzle'. Notably, the subgroup of parents working full-time are typically at a disadvantage. In the first phase of choosing, these parents already felt they had very limited choice, due to their busy working schedules and the characteristics of providers such as term-time opening hours, part-time free places and age ranges. These findings seem to be contrary to that of Leslie et al. (2000), who found that low-income mothers are more likely to be concerned with location; here the available choices of middle-class parents were often already tightly restricted to day nurseries and childminders located on their commuting route. Furthermore, they have to organise a full-day service which cannot be covered by the 30 free hours, and the fees for additional hours are growing by a larger rate than their wage (BBC News, 2017). The research findings that private and voluntary providers are generally of lower quality (Gambaro et al, 2015; Melhuish \& Gardiner, 2017) are relevant here, given the middle-class parents' reliance on this sector. We argue that fulltime working middle-class parents are operating in a particular distinct position in the childcare market, unless they have more flexible schedule or have enough income to 
combine a nanny with nursery school or a school-based nursery class. This is a notably different finding from previous studies where the middle classes as a whole were seen as benefitting from the market system (Grogan, 2012).

Secondly, this study contributes to existing knowledge of childcare choice being 'a series of inter-dependent decisions' (Chaudry, Henly, \& Meyers, 2010) by providing insights of the interaction between structural realities of the market and other factors, for instance, the need for a third phase of choosing where settings are equivalent, and the lack of availability motivating parents to make a decision before they expected. Another observation here is that, with the offer of free hours, worse-off participants in this study were less limited by their financial circumstances and had more autonomy to choose childcare based on other preferences, such as location and quality. However, this does not mean that less affluent parents have 'real choice' in the market given the fact that their choice scale is limited by the provision pattern of free hours, which does not support them to participate in the labour market as fully as they might have wished. These findings echo the analysis of 'inequality of autonomies' by Burchardt, Evans and Holder (2015), who pointed out that meaningful autonomous choice would not happen in a market where there is a lack of options that meet consumers' complex demands. Therefore, based on the above two findings, we argue that market structure should be particularly considered when understanding childcare choice in a given country.

Thirdly, this study corroborates the ideas of Heuristics and Biases Model, Social Network Model and Accommodation Model, which suggested that childcare decision is affect by subjective representation of the reality (Ross \& Nisbett, 1991), thus decision-makers would consciously and/or unconsciously look for cognitive 'shortcuts' from social networks (Chaudry et al., 2010). Some participants admitted that they did not have a wide search of information and made up mind based on personal experiences or information from significant others. Also, 'word of mouth' was frequently highlighted by parents to help them to map alternative options. However, beyond the 'close ties' that Henly, Danziger and Offer (2005) suggested, this research found parents referred to a wider network composed of 'other parents' in order to search different information. Given the social background of those participants, this is partly consistent with data obtained by Vincent et al. (2010), which suggested that middle-class parents are skilled in choice seeking. Implications of these findings are that there is a need to strengthen local authorities' role of providing information by being more parentfriendly, especially for lower income families, and providing an information platform for parents to share their childcare experiences of local providers.

Fourthly, this study lays the groundwork for future research to thoroughly examine how the factor of quality functions in parents' decision-making process. Chaudry and colleagues (2010) have noticed how different models view quality in a different way: (1) parents have their preference of quality; (2) parents face tradeoffs between quality and other factors; (3) parents are at a disadvantaged position due to the existence of information asymmetry with respect for quality, which means that it is difficult for them 
to 'see what they are buying' (Consumer Choice Model); (3) the function of quality might be hindered by 'availability heuristic' (Heuristics and Biases Model) or 'status quo bias' (Social Network Model); (4) parents with various social and economic capitals have 'persistent disparities' in the preference of quality (Accommodation Model). This study offered a more integral view with some new insights. To begin with, parents might be passively restricted by market and family realities like low availability, low income and time pressure to get access to higher quality provision. Apart from that, even the problem of information asymmetry is to some extent solved by established quality information (Ofsted ratings and reports), parents only take it as the 'starting point' and might intentionally choose not to select the top-rated settings (for example, 'outstanding is not necessary'). Third, parents might not recognize what research demonstrates about high quality childcare when they lay stress on the personality and attitude of practitioners rather than qualification and training. In addition, in contrast with the negative opinion of Liu (2015) and Peyton et al. (2001) towards parents' ability to judge childcare quality, we argue that parents actively offer a unique 'non-economic' (Penn, 2011) perspective of quality by emphasizing children's happiness and daily experience, which is largely absent in the present neoliberal performativity quality notions (Hunkin, 2018). Quality, in this research, appears to be a stable maternal feeling which is not fundamentally different, although it did vary across social-economic status.

\section{Conclusion}

The scope of this study was limited in terms of the scale of participants, and there is an imbalance in terms of social class. However, the study contributes to the international discussion about the dysfunction of neoliberal childcare markets (Hunkin, 2016, 2018a, 2018 b) by suggesting that parental choosing behaviours do not conform to the market logic of competition and choice. In the English mixed-economy childcare market, except for a few very affluent families, parents significantly lack 'real choice' through which they can balance family and work life. On top of that, each social class fraction is generally choosing within a restricted scale of the market, which does not cause general competition across the sector. Within each scale of the market, because parents might not be able to and/or do not want to pursue some key indicators of higher quality, i.e. staff qualification and training, parental choice is not actively stimulating quality improvement of providers, as suggested by the neoliberal model. It is also observed that government regulation leads to homogenized quality in some areas, and parents' quality preferences differ from the measurable quality notions of the neoliberalism discourse. Further research might be conducted in a given area with a larger scale and balanced number of participants of various social background. It might also be helpful to investigate to what extent public awareness campaigns about childcare quality and how these benefit children affect parental childcare choosing and market competition. Currently, the complex and dysfunctional system of childcare in England offers little 'real choice' for parents, whose choosing processes are limited by practical concerns including those inherent in the 'free hours' policy.

\section{Note}


1 'Disadvantaged' children are defined in this government policy as those with statements of special needs, those whose parents receive benefits and looked-after children under the care of the local authority (DfE, 2018).

\section{References}

Adamson, E., \& Brennan, D. (2014). Social investment or private profit? Diverging notions of 'investment' in early childhood education and care. International Journal of Early Childhood, 46(1), 47-61.

Anderson, S., Dawn, R., \& Scott, J. (2005). Illinois study of license exempt child care: Final report. Illinois: Springfield: Department of Human Services.

Azpitarte, F., Chigavazira, A., Kalb, G., Farrant, B. M., Perales, F., \& Zubrick, S. R. (2016). Childcare use and its role in Indigenous child development: Evidence from the Longitudinal Study of Indigenous Children in Australia. Economic Record.

BBC News, (2018) 'Parents shelling out for 'free' nursery scheme' Retrieved 7 November 2018 from: https://www.bbc.co.uk/news/education-42639258

BBC News, (2017) 'Childcare costs rise up to seven times faster than wages' Retrieved 4 April 2019 from https://www.bbc.com/news/uk-41690221

Blau, F. D., Ferber, M. A., \& Winkler, A. E. (2002). The Economics of Women, Men, and Work. Upper Saddle River, NJ: Prentice-Hall.

Blau DM (2001) The child care problem: an economic analysis. Russell Sage Foundation, New York

Boll, C. and Lagemann, A. (2019), Public Childcare and Maternal Employment New Evidence for Germany. Labour.

Burchardt, T., Evans, M., \& Holder, H. (2015). Public policy and inequalities of choice and autonomy. Social Policy \& Administration, 49(1), 44-67.

Campbell, T., Gambaro, L., \& Stewart, K. (2018). 'Universal'early education: Who benefits? Patterns in take - up of the entitlement to free early education among three - year - olds in England. British Educational Research Journal, 44(3), 515538.

Capizzano, J., \& Adams, G. (2004). Children in low-income families are less likely to be in center-based child care. Snapshots of America's Families III (Vol. 16). Washington, DC: Urban Institute.

Charmaz, K. (2006). Constructing grounded theory: A practical guide through qualitative analysis. Sage.

Chaudry, A., Henly, J., \& Meyers, M. (2010). ACF-OPRE White Paper. Conceptual Frameworks for Child Care Decision-Making. Office of Planning, Research and Evaluation, Administration for Children and Families, U.S. Department of Health and Human Services. Washington, DC.

Coley, R. L., Votruba-Drzal, E., Collins, M. A., \& Miller, P. (2014). Selection into early education and care settings: Differences by developmental period. Early childhood research quarterly, 29(3), 319-332.

Dahlberg, G., Moss, P., \& Pence, A. (2013). Beyond quality in early childhood education and care: Languages of evaluation. Routledge. 
De Marco, A. C. (2006). Child care options and choices for families on welfare in rural northern California counties. Unpublished dissertation, University of California, Berkeley.

DfE. (2018) Take-up of free early education entitlement, Retrieved 11 September 2018, from https://assets.publishing.service.gov.uk/government/uploads/system /uploads/attachment_data/file/738776/Takeup_of_free_early_education_entitlem ents.pdf

Emlen, A. C. (2010). Solving the childcare and flexibility puzzle: How working parents make the best feasible choices and what thatmeans for public policy. Boca Raton, Florida: Universal-Publishers.

Gallagher, A. (2018). The business of care: Marketization and the new geographies of childcare. Progress in Human Geography, 42(5), 706-722.

Gambaro, L., Stewart, K., \& Waldfogel, J. (2015). A question of quality: do children from disadvantaged backgrounds receive lower quality early childhood education and care? British Educational Research Journal, 41(4), 553-574.

Grogan, K. E. (2012). Parents' choice of pre-kindergarten: The interaction of parent, child and contextual factors. Early child development and care, 182(10), 12651287.

Harding, C. \& Cottell, J. (2018) Childcare Survey 2018, Family and Childcare Trust, Retrieved 7 November 2018 from: https://www.familyandchildcaretrust.org/childc are-survey-2018

Henly, J. R., Danziger, S. K., \& Offer, S.(2005). The contribution of social support to the material well-being of welfare recipients. Journal of Marriage and Family, 67, 122-140.

Huff, A. D., \& Cotte, J. (2013). Complexities of consumption: The case of childcare. Journal of Consumer Affairs, 47(1), 72-97.

Hunkin, E. (2016). Deploying Foucauldian genealogy: Critiquing 'quality'reform in early childhood policy in Australia. Power and Education, 8(1), 35-53.

Hunkin, E. (2018a). If not quality, then what? The discursive risks in early childhood quality reform. Discourse: Studies in the Cultural Politics of Education, 1-13.

Hunkin, E. (2018b). Whose quality? The (mis) uses of quality reform in early childhood and education policy. Journal of Education Policy, 33(4), 443-456.

Huskinson, T., Hobden, S., Oliver, D., Keyes, J., Littlewood, M., Pye, J., and Tipping, S. (2016) Childcare and Early Years Survey of Parents 2014 to 2015, Department for Education Research Report DFE-00064-2016, London: DfE.

Huston, A. C., Chang, Y. E., \& Gennetian, L. (2002). Family and individual predictors of child care use by low-income families in different policy contexts. Early Childhood Research Quarterly, 17(4), 441-469.

Johansen, A., Leibowitz, A., \& Waite, L. (1996). The importance of child-care characteristics to choice of care. Journal of Marriage and the Family, 58, 759772.

Katz, L. G. (1993). Multiple perspectives on the quality of early childhood programmes. European Early Childhood Education Research Journal, 1(2), 5-9. 
Leslie, L. A., Ettenson, R., \& Cumsille, P. (2000). Selecting a child care center: What really matters to parents? Child and Youth Care Forum, 29, 299-322.

Liu, M. (2015). An ecological review of literature on factors influencing working mothers' child care arrangements. Journal of Child and Family Studies, 24(1), 161-171.

Mahon, R. (2010). After neo-liberalism? The OECD, the World Bank and the child. Global Social Policy: An Interdisciplinary Journal of Public Policy and Social Development, 10(2), 172-192.

Mathers, S., Ranns, H., Karemaker, A., Moody, A., Sylva, K., Graham, J., \& SirajBlatchford, I. (2011). Evaluation of the graduate leader fund. Report to the UK Department of Education, 28.

Melhuish, E., \& Gardiner, J. (2017). Study of Early Education and Development (SEED): Study of Quality of Early Years Provision in England. London: Department for Education.

Meyers, M. K., \& Jordan, L. P. (2006). Choice and accommodation in parental child care decisions. Community Development, 37(2), 53-70.

Mocan, N. (2007). Can consumers detect lemons? An empirical analysis of information asymmetry in the market for child care. Journal of population Economics, 20(4), 743-780.

Mittelstaedt, J. D., Duke, C. R., \& Mittelstaedt, R. A. (2009). Health care choices in the United States and the constrained consumer: A marketing systems perspective on access and assortment in health care. Journal of Public Policy \& Marketing, 28(1), 95-101.

Nutbrown, C. (2012). Foundations for quality: the independent review of early education and childcare qualifications.

OECD. (2004). Babies and Bosses-Reconciling Work and Family Life (Volume 4): Canada, Finland, Sweden and the United Kingdom. Organisation for Economic Co-operation and Development..

Peyton, V., Jacobs, A., O’Brien, M., \& Roy, C. (2001). Reasons for choosing child care: Associations with family factors, quality, and satisfaction. Early Childhood Research Quarterly, 16, 191-208.

Penn, H. (2011). Quality in Early Childhood Services: An International Perspective. Maidenhead: Open University Press.

Penn, H., \& Randall, V. (2005). Childcare policy and local partnerships under Labour. Journal of Social Policy, 34(1), 79-97.

Powell, L. M. (2002). Joint Labor Supply and Childcare Choice Decisions of Married Mothers. Journal of Human Resources, 37(1): 106-128.

Raikes, H., Torquati, J., Wang, C., \& Shjegstad, B. (2012). Parent experiences with state child care subsidy systems and their perceptions of choice and quality in care selected. Early Education \& Development, 23(4), 558-582.

Radey, M., \& Brewster, K. L. (2007). The influence of race/ethnicity on disadvantaged mothers' child care arrangements. Early Childhood Research Quarterly, 22, 379-392.

Ross, L., \& Nisbett, R.E. (1991). The person and the situation: Perspectives of social 
psychology. New York: McGraw-Hill.

Speight, S., Maisey, R., Chanfreau, J., Haywood, S., Lord, C., Hussey, D. (2015)

Study of Early Education and Development: Baseline survey of families. London: National Centre for Social Research.

Stewart, K., \& Gambaro, L. (2014). World Class: what does international evidence tell us about improving quality, access and affordability in the English childcare market?. [2018-5-21]. http://dera.ioe.ac.uk/28295/

Savage, M., Devine, F., Cunningham, N., Taylor, M., Li, Y., Hjellbrekke, J., ... \& Miles, A. (2013). A new model of social class? Findings from the BBC's Great British Class Survey experiment. Sociology, 47(2), 219-250.

Van Gameren, E. (2013). The role of economic incentives and attitudes in participation and childcare decisions. Journal of family and economic issues, 34(3), 296-313.

Vincent, C., \& Ball, S. (2006). Childcare Choice and Class Practices. London: Routledge.

Vincent, C., \& Ball, S. J. (2001). A market in love? Choosing pre-school childcare. British Educational Research Journal, 27 (5), 632-651

Vincent, C., Ball, S., \& Kemp, S. (2004). The social geography of childcare: 'making up' the middle class child. British Journal of Sociology of Education, 25 (2), 229244. doi:10.1080/0142569042000205091

Vincent, C., Braun, A., \& Ball, S. (2010). Local links, local knowledge: choosing care settings and schools. British Educational Research Journal, 36(2), 279 - 298. doi:10.1080/01411920902919240

West, A., \& Noden, P. (2018). 'Nationalising'and Transforming the Public Funding of Early Years Education (and care) in England 1996-2017. British Journal of Educational Studies, 1-23. 
Table 1. Participants' background information

\begin{tabular}{l|lllll} 
NO. & NAME & WAY OF RECRUITMENT & PARENT BACKGROUND & FREE HOURS \\
\hline $\mathbf{0 1}$ & Isla & Responded to call for parents & Full time work & Middle Class & Free 30 hours plus top up \\
$\mathbf{0 2}$ & Lily & From nursery class & Part time work & New Affluent workers & Free 15 hours \\
$\mathbf{0 3}$ & Grace & From nursery class & Stay-at-home & Middle Class & No free hours \\
$\mathbf{0 4}$ & Chloe & From private school & No paid work & Middle Class & No free hours \\
$\mathbf{0 5}$ & Wendy & From private school & Full time work & Middle Class & No free hours \\
$\mathbf{0 6}$ & Ruby & Responded to call for parents & Full time work & Middle Class & No free hours \\
$\mathbf{0 7}$ & Carol & From nursery school & Part time work & Working Class & Free 30 hours \\
$\mathbf{0 8}$ & Jessica & From nursery school & Part time work & Working Class & Free 30 hours \\
$\mathbf{0 9}$ & Eva & Responded to call for parents & Full time work & Middle Class & No free hours \\
$\mathbf{1 0}$ & Becky & Responded to call for parents & Full time work & Middle Class & Free 30 hours plus top up \\
$\mathbf{1 1}$ & Fiona & Responded to call for parents & Full time work & Elite & Free 15 hours plus top up \\
$\mathbf{1 2}$ & Maya & From nursery school & Part time work & Middle Class & Free 30 hours plus top up \\
$\mathbf{1 3}$ & Georgia & From voluntary nursery & On maternity leave & Middle Class & Free 30 hours plus top up \\
$\mathbf{1 4}$ & Holly & From voluntary nursery & Part time work & Elite & No free hours \\
$\mathbf{1 5}$ & Daisy & Responded to call for parents & Full time work & Middle Class & Free 15 hours plus top up \\
$\mathbf{1 6}$ & Phoebe & Responded to call for parents & Part time work & Middle Class & Free 15 hours plus top up \\
$\mathbf{1 7}$ & Joan & From voluntary nursery & Part time work & Elite & No free hours
\end{tabular}


Table 2 Provision types participants considered and used

\begin{tabular}{|c|c|c|c|c|c|c|c|}
\hline No. & Name & $\begin{array}{l}\text { Day } \\
\text { nursery }\end{array}$ & $\begin{array}{l}\text { Childminder } \\
\text { /nanny }\end{array}$ & $\begin{array}{l}\text { Voluntary } \\
\text { nursery }\end{array}$ & $\begin{array}{l}\text { nursery } \\
\text { class in } \\
\text { school }\end{array}$ & $\begin{array}{l}\text { Nursery } \\
\text { school }\end{array}$ & $\begin{array}{l}\text { Informal } \\
\text { care }\end{array}$ \\
\hline 01 & Isla & $\sqrt{ }$ & & & & & \\
\hline 02 & Lily & $x$ & & & $\sqrt{ }$ & & $\sqrt{ }$ \\
\hline 03 & Grace & $x$ & & & $\sqrt{ }$ & & $\sqrt{ }$ \\
\hline 04 & Chloe & $\sqrt{ }$ & & & $\sqrt{ }$ & & \\
\hline 05 & Wendy & $\sqrt{ }$ & & & $\sqrt{ }$ & & \\
\hline 06 & Ruby & & $\sqrt{ }$ & & & & \\
\hline 07 & Carol & $x$ & & & & $\sqrt{ }$ & $\sqrt{ }$ \\
\hline 08 & Jessica & $x$ & & & & $\sqrt{ }$ & $\sqrt{ }$ \\
\hline 09 & Eva & $\sqrt{ }$ & & & & & \\
\hline 10 & Becky & $\sqrt{ }$ & & & & & \\
\hline 11 & Fiona & $\sqrt{ }$ & $\sqrt{ }$ & & & $\sqrt{ }$ & \\
\hline 12 & Maya & $x$ & & & & $\sqrt{ }$ & $\sqrt{ }$ \\
\hline 13 & Georgia & $x$ & $\sqrt{ }$ & $\sqrt{ }$ & & & \\
\hline 14 & Holly & $\sqrt{ }$ & $\sqrt{ }$ & $\sqrt{ }$ & & & \\
\hline 15 & Daisy & $\sqrt{ }$ & & & & & \\
\hline 16 & Phoebe & $\sqrt{ }$ & & & & & $\sqrt{ }$ \\
\hline 17 & Joan & $x$ & $\sqrt{ }$ & $\sqrt{ }$ & & & \\
\hline
\end{tabular}

Note: "ل" indicates that parents used the provision; " $\times$ " indicates that parents considered the option but did not use it. 
Table 3 Parents' judgement of ECEC quality

\begin{tabular}{|c|c|c|c|}
\hline $\begin{array}{l}\text { Quality } \\
\text { subscales }\end{array}$ & Quality items & Parents descriptions & $\begin{array}{l}\text { Number of } \\
\text { parents }\end{array}$ \\
\hline \multirow{5}{*}{$\begin{array}{l}\text { Space\& } \\
\text { furnishings }\end{array}$} & Indoor space & $\begin{array}{l}\text { light/dark, clean, space for children, small, closed in, fresh } \\
\text { air }\end{array}$ & 7 \\
\hline & $\begin{array}{l}\text { Furniture and routine care, play and } \\
\text { learning }\end{array}$ & good range of resources, smaller/children size toilet, toys & 2 \\
\hline & Room arrangement for play & Sensory room & 1 \\
\hline & Gross motor equipment & outdoor play area & 8 \\
\hline & Furnishing for relaxation and comfort; & Space for privacy & / \\
\hline \multirow{3}{*}{$\begin{array}{l}\text { Personal } \\
\text { care } \\
\text { routines }\end{array}$} & Safety practices & Safety, CCTV & 5 \\
\hline & Meals/snacks & hot meals & 1 \\
\hline & \multicolumn{2}{|c|}{ Greeting/departing; Nap/rest; Toileting/diapering; Health practices } & / \\
\hline \multirow{4}{*}{ Activities } & $\begin{array}{lrr}\text { Art, } \quad \text { Music/movement; } & \text { Blocks; } \\
\text { Sand/water; } \quad \text { Dramatic } & \text { play; } \\
\text { Nature/science; } & \text { Math/number }\end{array}$ & $\begin{array}{l}\text { lots of activities, music playing outside, learning things, } \\
\text { school preparation }\end{array}$ & 4 \\
\hline & Use of TV/video/computers & watch too much TV & 1 \\
\hline & Promoting acceptance of diversity & $\begin{array}{l}\text { celebrate different types of culture festivals, another } \\
\text { language }\end{array}$ & 2 \\
\hline & Fine motor & & / \\
\hline \multirow{2}{*}{ Interactions } & General supervision of children & $\begin{array}{l}\text { friendly, nice, warm, caring, nurturing, watching the } \\
\text { children, cold, attentive, look after, helpful, general care, } \\
\text { intimate, atmosphere, one on one care }\end{array}$ & 17 \\
\hline & Staff-child interactions & $\begin{array}{l}\text { disinterested, connection, support children, interaction with } \\
\text { children, behavior, how they are with the children, engaging }\end{array}$ & 8 \\
\hline
\end{tabular}




\begin{tabular}{|c|c|c|c|}
\hline & & $\begin{array}{l}\text { with children, how they treat children, physical contact, } \\
\text { passionate, boring }\end{array}$ & \\
\hline & $\begin{array}{l}\text { Interactions among children } \\
\text { Discipline }\end{array}$ & $\begin{array}{l}\text { kids know each other, friendship, } \\
\text { If children being mean to each other, are the staffs making } \\
\text { sure they apologies. }\end{array}$ & 3 \\
\hline & Supervision of gross motor activities & & 1 \\
\hline \multirow{3}{*}{$\begin{array}{l}\text { Program } \\
\text { structure }\end{array}$} & Schedule, & structural day, not structural/formal, & 2 \\
\hline & Free play & free-flow, children centered, learn through play & 7 \\
\hline & Group time; Provision for children with & disabilities & / \\
\hline \multirow{3}{*}{$\begin{array}{l}\text { Parents\& } \\
\text { staff }\end{array}$} & Provision for parents & family friendly & 1 \\
\hline & Staff interaction and cooperation & how staff speak to each other & 1 \\
\hline & $\begin{array}{l}\text { Supervision and evaluation of staff; } O_{t} \\
\text { needs of staff/ professional needs of st }\end{array}$ & $\begin{array}{l}\text { pportunities for professional growth; Provision for personal } \\
\text { taff }\end{array}$ & / \\
\hline \multirow{4}{*}{ Non ECERS-R } & Building & modern, purposely built, nice old big house & 2 \\
\hline & Ratio/group size & $\begin{array}{l}\text { class size, smaller group, right ratio (almost given), a lot } \\
\text { children }\end{array}$ & 6 \\
\hline & Children emotional wellbeing & happy, ready, confident, frustrated, intense, upset, crying & 13 \\
\hline & & $\begin{array}{l}\text { male staff, mix of age, junior, more teachers, qualified } \\
\text { teacher }\end{array}$ & 5 \\
\hline
\end{tabular}

Note: (1) Each of the 17 parents surveyed have mentioned more than one item; (2) The subscale of 'Language and reading' was not mentioned.

Figure 1 English parents' childcare and education choosing phases 


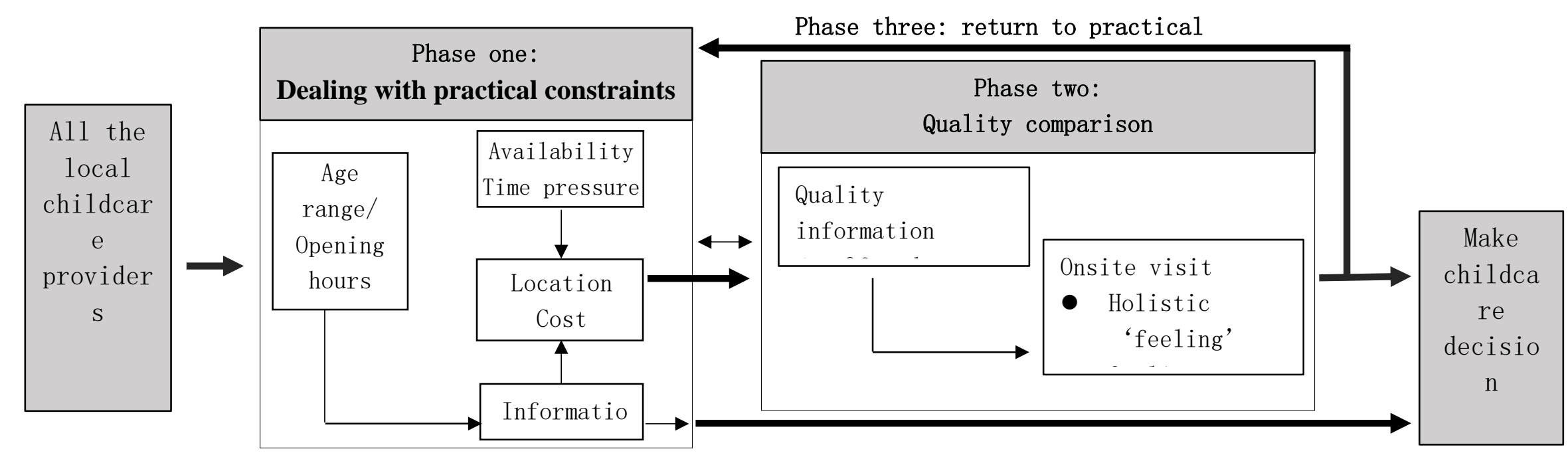

